\title{
Researches on Cognitive Process and Their Applications to Organizational Change in Information Systems
}

\author{
Jaesung Sim
}

\begin{abstract}
Government intervention, industry cooperation, new vendors, and foreign competition are all factors that exert a powerful influence on the information technology, marketplace, and on the individual IS organization. When these influences need to change an organization, it is likely the culture or identity of the organization will be targeted for change. Because an organization is also composed of cognitive frameworks, there is an implication that the existing cognitive structures are in jeopardy. Thus, the cognitive component is important in how all members of organizations react and respond to change.

This paper defines cognitive process and its related research history, introduces organizational change matters, tries to solve conflicts in organizational changes, and applies this topic to the information systems field.
\end{abstract}

Index Terms - Cognitive Process, Information Systems, Organizational Change

\section{INTRODUCTION}

Government intervention, industry cooperation, new vendors, and foreign competition are all factors that exert a powerful influence on the information technology, marketplace, and on the individual IS organization. When these influences need to change an organization, it is likely the culture or identity of the organization will be targeted for change. Because an organization is also composed of cognitive frameworks, there is an implication that the existing cognitive structures are in jeopardy. Thus, the cognitive component is important in how all members of organizations react and respond to change.

This paper defines cognitive process and its related research history, introduces organizational change matters, tries to solve conflicts in organizational changes, and applies this topic to the information systems (IS) field.

\section{COGNITIVE PROCESS LITERATURE}

\section{A. What is Cognitive Process?}

Information systems (IS) in organizations support human decisions by providing decision makers with relevant information. Hence, the human decision maker is the prime target of any information that is processed and displayed by

Manuscript received August 31, 2012.

Jaesung Sim is with Department of Mathematics and Computer Information Science, Mansfield University of Pennsylvania, Pennsylvania 16933 U.S.A., Tel: +1-570-662-4704, E-Mail: jsim@ mansfield.edu computerized or manual facilities. Human information processing is achieved through a complex and not completely understood mechanism called the cognitive process.

Lindsay and Norman (1977) examined cognitive process and found that a prerequisite to any human perception is paying attention. Being attentive enables us to detect and identify a stimulus so that we can transfer its message for further processing. The location of further processing is in the short-term memory (STM), in which the information is held no more than a few seconds. The majority of the analysis of the information is performed in the long-term memory (LTM), where it is classified, stored, and analyzed, perhaps triggering a decision to react. Miller (1956) discovered the capacity of STM is limited to about seven units of information plus or minus two.

Newell and Simon (1972) developed a formal model of human information processing for use in research on artificial intelligence. If we substitute some terms of Lindsay and Norman (1977) with some others of Newell and Simon (1972), we get a description of a computer system. Data enter into the system via input devices (receptors - identification); are processed by CPU (central processing unit - reaction); are stored in registers (STM), internal storage (LTM), and external storage devices (external memory - LTM); and are displayed via output devices (effectors - reaction).

Spence and Tsai (1997) viewed cognitive process as dynamic or the reflection of a state - the approaches used in sensing, concept formation, decision making, and problem solving.

\section{B. How cognition is researched in the IS field?}

In 1973, Mason and Mitroff proposed PPPOEM that "An information system consists of at least one PERSON of a certain PSYCHO-LOGICAL type who faces a PROBLEM within some ORGANIZATIONAL CONTEXT for which he needs EVIDENCE to arrive at a solution, and that the evidence is made available through some MODE of PRESENTATION."

With this framework, Mason and Mitroff (1973) helped set in motion the concept that the human component was an important and viable piece of the information system and was worthy of researching. Mason and Mitroff (1973) set a tentative principle that managers need information that is geared to THEIR PSYCHOLOGY not to that of their designer. Mason and Mitroff (1973) was not the first to suggest the importance of studying the human factor, specifically within an 
IS framework. However, Mason and Mitroff's (1973) framework is considered to be the first real attempt towards a scientific approach to studying IS, and their emphasis on the human side of the equation should not be downplayed. Their measure of personality type was based on the Myers Briggs Type Indicator (MBTI) which is intended to measure the personality aspects of cognitive style.

Chervany, Dickson and Kozar (1972) presented a framework that also focused on the human component in their examination of various influences (e.g. the decision maker, the decision environment, and the characteristics of the information system) on the effectiveness or quality of a decision. Chervany et al. (1972) stated that due to differences in cognitive style, what is information to one person might not be information to another person.

Ives, Hamilton and Davis (1980) continued to support the notion of the importance of the human component as they, in their framework, included three IS environmental variables, the Information Subsystem (ISS), and three IS process variables related to the user. Environmental variables define resources and constraints that dictate the scope and form of each information subsystem: external, organizational, user, IS development, and IS operations. The Information Subsystem (ISS) is the output of the development process: ISS content, presentation form, and time of presentation. Process Variables are measures of the interactions between the IS and the environment: development process, operational process, and use process

Nolan and Wetherbe (1980) added the concept of feedback in their framework, decidedly a requirement in the effective processing of information by humans. Nolan and Wetherbe (1980) proposed that systems theory can be applied to developing an MIS research framework by viewing MIS as an open system which transforms data, requests for information, and organized resources (inputs) into information (outputs) in the context of an organization (environment of MIS). Nolan and Wetherbe (1980) proposed that MIS research can be broadly defined as pertaining to the transformation process of MIS or to the environmental interaction of MIS. Thus, research into various cognitive style issues continued.

However, Huber (1983) examined the human component and the cognitive style research conducted to date and developed the opinion that this research focus was "Much Ado about Nothing" and strongly suggested discontinuing this fruitless area. Huber (1983) suggested that the IS cognitive style research is weak and inconclusive; where cognitive style has been shown to have an impact it only explains a small percentage of the variance. He suggested that past studies have not provided any operational guidelines for MIS/DSS design; in addition, future studies are not likely to provide meaningful guidelines for MIS/DSS design. He proposed that we lack effective measurement tools for measuring cognitive style. Thus IS researchers should focus on more fruitful domains and cognitive style is potentially useful for career counseling, personnel selection/placement, and coaching/training.

Robey (1983) responded to Huber's criticisms and commented that continuing research into human factors could lead to insight into how to better develop systems. Robey (1983) commented that cognitive style may be useful for discovering a basis for MIS/DSS design, and neglecting cognitive style research will do nothing to improve MIS/DSS design. Robey and Taggert $(1981,1982)$ conducted research into the cognitive areas as well, specifically in regards to the effect of cerebral dominance. The specific findings gained from Robey and Taggert's (1981, 1982) work included the notion that to support right-brained (intuitive) thinking, graphics should be presented on the left side of the screen, and that to support left-brain (analytical) thinking, text should be presented on the right side of the screen. Thus, even with Huber's strong criticisms, research into cognitive style and the human component continued.

Then, Ramaprasad (1987) suggested that there is a mismatch between IS research and MIS/DSS design. Ramaprasad (1987) reexamined the work of Posner and McLeod's (1982) taxonomy of decisions \& strategies to point out that IS researchers have been concentrating on macro level influence (cognitive style) while IS practitioners have been designing applications that support dynamic structures and processes (cognitive process). Ramaprasad (1987) discussed the difference between cognitive style and cognitive process, style being much more enduring (trait based) while process was much more transient (state based). Ideally, because research is supposed to support practice, Ramaprasad (1987) suggested that the focus should be on a more micro (process) level versus a macro (style) level. His conclusion - if the information systems field is to fulfill its mission of supporting decision making, it should focus its research on cognitive process issues. Todd and Benbasat (1987, 1991), for example, performed research into various types of process tracing to help determine what actually went on in a person's mind as they were performing a task or making a decision. Spence and Tsai (1997) offered evidence suggesting that cognitive process may better explain differences in human performance across multiple tasks.

The research into the human component took another slight turn when Vessey (1991), Vessey and Galletta (1991) suggested the notion of cognitive fit - a favorable mental state of the problem solving process that occurs when the problem representation and the task match. Vessey and Galletta (1991) proposed that designers should concentrate on determining the characteristics of the tasks that problem solvers must address, and on supporting those tasks with the appropriate problem representations and support tools. The paradigm of cognitive fit is based on the use of consistent decision making processes both to act on the problem representation and to solve the problem. Vessey and Galletta (1991) addressed practitioners by suggesting that their work will help problem solvers to choose an appropriate problem representation to support the information acquisition task. 
Research continues into all aspects of the human component. For example, Bostrom, Olfman and Sein (1990) examined the issue of learning style and end user training. Furthermore, there is some debate over exactly what makes up cognitive style. Many assume that it is an almost permanent aspect of an individual's behavior, whereas others consider it to be simply a propensity to choose one way or another, with the option of selecting a different style should the situation warrant.

Rao, et al. (1992) presented a commentary on the paper of Robey and Taggert (1982) by contending that research focus should be on the psychological issues where cognitive functions are studied independently of their physical implications. Robey (1992) responded back to Rao, et al. by asserting that DSS research programs must include social interpretation. Gregor and Benbasat (1999) used cognitive effort perspective and cognitive learning theory to build the rationale why explanations should be provided in Intelligent Systems. Te'eni (2001) used a communication cognitiveaffective process to describe the choice of one or more communication strategies, the form of the messages, and the medium through which it is transmitted.

Griffith and Northcraft (1996) explored the major mechanisms that differences in cognitions among users, designers, and implementers can determine the success or failure of implementation. Compeau, Higgins, and Huff conducted a longitudinal study in 1999, and found that computer adoption and use is not just about convincing people of the benefits to be derived from the technology. It must also be about coaching, teaching, and encouraging individuals to acquire the skills necessary for them to be successful in their computer use.

Agarwal and Karahanna (2000) labeled a new construct, cognitive absorption, and defined as a state of deep involvement with software. Cognitive absorption is posited to be a proximal antecedent of two important beliefs about technology use, perceived usefulness and perceived ease of use. Another important research was conducted by Shaft and Vessey in 2006. They specified that cognitive fit exists when the software maintainer's dominant mental representation of the software and their mental representation of the modification task emphasize the same type of knowledge. When cognitive fit exists, greater improvements in comprehension are associated with higher levels of performance on a modification task. When cognitive fit does not exist, however, the software maintainer's mental representations of the software and of the modification task do not emphasize the same type of knowledge, which may mean that attention is devoted to comprehension at the expense of modification, resulting in lower performance on the modification task (Shaft and Vessey, 2006).

Despite on-going criticisms regarding the appropriateness to IS research, work continues and gradually the field is gaining in understanding as to how best to meet the needs of the decision makers - the primary focus of an IS.

\section{Cognitive Process in ORganizational Change}

\section{A. General Concept of Organizational Change}

Introduction of a new perspective usually leads to conflict among organizational members who have varying levels of agreement with it. Change agents typically imagine that despite initial resistance to their initiatives, the long-term result of the actions they take will be positive and consistent with their aspirations.

When change is needed in an organization, it is likely the culture or identity of the organization will be targeted for change. Because an organization is also composed of cognitive frameworks, there is an implication that the existing cognitive structures are in jeopardy.

Recipients of the intended change frequently view a new perspective differently from the ways the change agents do. Their reactions to the new perspective will depend in part on how much implementation corresponds to the rules they associate with the perspective. When expectations are not met, the likely outcome is some type of conflict.

Bartunek, Lacey and Wood (1992) insisted that certain cognitive processes are likely to be evoked in a group or organization when a new schema (perspective) is introduced and that conflicts are likely to arise because of these cognitive processes.

New schemas (e.g. information systems) are not installed in a vacuum. They are inserted into living organizations that maintain common practices, habits, and attitudes. Newly arrived systems might shake delicate equilibriums among various parties. They might encourage or interfere with personal or group ambitions. Consequently, they may be fostered or opposed because of the current psychological climate, not because of their "objective" technical quality (Ward, 1998).

The psychological climate affects information systems at all stages of the life cycle. It may trigger an initiative to develop a new system, but it may also extinguish new ideas. It influences the level of user cooperation while systems are developed. It generates receptiveness or opposition during implementation. It regulates the frequency of use, and hence the success, of systems after they have been installed. Understanding and proper treatment of psychological climates are vital if information systems are to be useful.

It is likely that their primary response to the new system or new schema will be to "make sense" of the new understanding being introduced, especially if it is different from and threatening to their present way of understanding. Their sense making will include both construal and social categorization processes.

When a new schema is being introduced in an organization, organizational members are likely to construe the schema in some particular way, develop some prototype for the schema along with exemplars for it, and assess change agent's activities to determine if they correspond with these prototypes and exemplars (Schneider, 1991). These cognitive processes affect responses to the attempted change (Bartunek, Lacey and 
Wood, 1992).

\section{B. Organizational Change in Multiple Workgroups}

Larkey (1996) developed a theory of communicative interactions. This theory is used to examine the conditions and situations that affect groups with racial, cultural, and gender diversity and to predict the sorts of interactions expected under those conditions. Larkey (1996) found 7 Propositions in culturally diverse workgroups, the type of cognitive processing influences communication networks, evaluations made about cultural differences, ideation, and understanding.

Factors that influence cognitive processes are made salient by the theory and may be used as a teaching tool, so that individuals may watch for those conditions and assess their responses more critically as they anticipate them.

\section{Resistance to Change}

Resistance to change is a typical phenomenon in any kind of organization whenever an innovative process (schema) is introduced to a group of individuals. However, the fast advancement of computerized systems has increased the intensity of this problem.

Bakos and Treacy (1986) offered five possible explanations for the resistance of some senior managers to a more proactive role for the IS manager. One is ignorance of information technology and its potential uses and benefits. Another reason is poor communication between the IS department and the rest of business. A third reason is a general resistance to change, of any sort, common among both IS and other personnel. The fourth and fifth reasons offered by Bakos and Treacy (1986) are lack of focus on opportunities for competitive advantage and a lack of instruments for decisively measuring the benefits of information technology.

Sociological research indicated that the process of change in individuals, as well as in groups, consists of the following stages: unfreezing, moving, and refreezing (Schein 1961). Resistance to change reflects an incomplete or unsuccessful unfreezing. It means 1) Subjects are not motivated enough, or 2) They fear change more than they value probable benefits.

\section{How organizational change conflicts are accomplished?}

There are several approaches to overcome organizational change problems in social science researches.

Poole (1998) examined the cognitive process that is at work when members of an organization become aware that their organization is in a state of change or transformation. Poole (1998) proposed that transformation success is affected by the congruency between managerial words and deeds during the transformation period. Inconsistency of managerial words and deeds will create organizational dilemma and/or chaos which will seriously impede or destroy the transformation.

Hammersley, Kadous and Magro (1997) proposed that the explanation effect causes an event to seem more likely after the decision maker has explained it. Belief perseverance research suggests that the causal evaluation of evidence leads to cognitive changes that cause an event that is explained by the decision maker to be judged more likely to occur than an event that is not explained by the decision maker. This difference in perceived likelihood has been termed the explanation effect. There are at least two distinct interpretations of the explanation effect. One interpretation is that the act of explaining an event causes a decision maker to think about instances of that event. A second cognitive interpretation is that when confronted with the task of explaining an event or outcome, a decision maker builds a causal mental representation of the scenario.

Most people tend to resist switching from an automatic to a conscious, reflective mode of thinking under conditions of ambiguity and threat. Friedman and Lipshitz (1992) suggested that resistance to switching cognitive gears is related to the extent of "reconceptualization", that is, to the degree to which learners must consciously change and reorganize their existing system of cognitive categories in order to make sense of their experience.

Some help to overcome resistance of senior managers was afforded by a model developed by Rockart and Crescenzi (1984). This model consists of three phases.

Phase 1: Linking information systems to business management needs (introductory workshop, critical success factors interviews, focusing workshop).

Phase 2: Developing systems priorities and gaining confidence in recommended systems (critical measures evaluation workshop, development of systems priorities, observation of decision process and business flow, decision scenario workshop).

Phase 3: Rapid development of low-risk, managerially useful systems (creation of prototype design, systems development, evaluation and institutionalization).

The result of this three-phase process is that senior management becomes involved more quickly and in meaningful ways, and keeps its attention on the development process throughout.

\section{Cognitive Process in Organizational Change In the} IS FIELD

\section{A. What are the challenges in the IS organization?}

Organizations have come to rely on technological innovation as a central component of their competitive strategy (Reddy, 1990). While new technologies hold tremendous promise for enhancing organizations' efficiency and effectiveness, much of this potential is never realized. One study of 2,000 U.S. companies found that 40 percent had not achieved the intended benefits from implementing an office technology (Bikson and Gutek, 1984). Significantly, less than 10 percent of these implementation failures appeared to stem from technical problems; most occurred for human and organizational reasons, such as poor technology management (Bikson and Gutek, 1984), including users' misunderstanding of the meaning and/or uses of the technology.

The top 10 major organizational challenges facing the 
information systems managers were determined as a result of an extensive survey of IS managers reported by Brancheau and Wetherbe (1987). Three of ten are considered important in this paper: Aiding organizational learning, Realigning information systems in the organization, and Dealing with enduser computing.

\section{B. How these challenges are overthrown?}

Four approaches to overcome conflicts in organizational change in above section may be the answers for overthrowing challenges: congruency between managerial words and deeds, explanation by the decision maker, reconceptualization, and three-phase model developed by Rockart and Crescenzi (1984).

However, Griffith and Northcraft (1996) suggested a more significant approach. Griffith and Northcraft (1996) offered the fine-grained model to view how user and implementer understandings influence implementation success. For attitudes, users' perceptions of having enough time to adjust to the new technology produced a main effect; both satisfaction and feelings of expertise were positively related to users' perceptions of having enough time. Balanced information significantly affected performance; however, limited information (positive description bias) -combined with perceptions of enough time to work with the technology also yielded high performance.

Understanding cognitive process is essential to solve problems in organizational change. Davidson (2002) suggested that improving our understanding of socio-cognitive processes is also important in requirement determination during information system delivery. Zhuge (2003) defined a new notion of cognitive flow to reflect the dynamic cognition processes of a team. Knowledge management in networks is a cognitive process, too (Schamp et. al. 2004).

Nevelli and Mohally (2004) indicated all of the participants should have a sense of ownership of the challenge to lessen employ resistance. They concluded that a stepped approach is necessary for the organization's employees to ensure that a dramatic change, such as customer relationship management (CRM), will be accepted at every level. Mukherjee and D'Souza (2003) proposed that phased implementation for organizational change, especially for data warehousing implementation process, can improve the chance of success.

Ratnasingam (2005) examined the impact of technology trust within an inter-organizational dyad between Cisco and Compaq. He found that if organizations believe that the underlying technology infrastructure is capable of facilitating transactions according to their confident expectations, then this technology trust contributes and evolves into relationship trust.

The key is to anticipate problems -- whether technological or organizational - and provide new users with costless ways to learn to solve them. (e.g., free training may need to address organizational issues as well as technological ones).

\section{CONCLUSIONS AND FUTURE RESEARCH}

Various studies have been collected and summarized regarding human component in IS research. However, it is not possible to suggest that only one certain idea as the ideal basis for solution in organizational change problems. Thus, a part of future research should focus on evaluating all approaches in this paper and/or on determining the best approach or combining multiple feasible approaches.

\section{REFERENCES}

[1] Agarwal, R., and Karahanna, E. (2000), "Time Flies When You're Having Fun: Cognitive Absorption and Beliefs about Information Technology Usage", MIS Quarterly, Vol. 24.4, pp. 665-694.

[2] Bakos, J. Y., and Treacy, M.E. (1986), "Information Technology and Corporate Strategy: A Research Perspective," MIS Quarterly, Vol.10.2, pp. 107-119.

[3] Bartunek, J. M., Lacey, C. A., and Wood, D.R. (1992), "Social Cognition in Organizational Change: An Insider-Outsider Approach", Journal of Applied Behavioral Science, Vol. 28.2, pp. 204-223.

[4] Bikson, T., and Gutek, B. (1984), "Implementation of Office Automation," Rand Corporation, Santa Monica, CA.

[5] Bostrom, R. P., Olfman, L., and Sein, M.K. (1990), "The Importance of Learning Style in End-User Training”, MIS Quarterly, Vol. 14.1, pp.101-119.

[6] Brancheau, J. C., and Wetherbe, J. C. (1987), "Key Issues in Information Systems Management," MIS Quarterly, Vol. 11.1, pp. 2345.

[7] Chervany, N.L., Dickson, G.W., and Kozar, K.A. (1972), "An Experimental Gaming Framework for Investigating the Influence of Management Information Systems on Decision Effectiveness," Working Paper 71-12, Management Information Systems Research Center, University of Minnesota, Minneapolis, MN.

[8] Compeau, D., Higgins, C., and Huff, S.(1999), "Social Cognitive Theory and Individual Reactions to Computing Technology: A Longitudinal Study," MIS Quarterly, Vol. 23:2, pp. 145-158.

[9] Davidson, E.J. (2002), "Technology Frames and Framing: A SocioCognitive Investigation of Requirements Determination", MIS Quarterly, Vol. 26.4, pp. 329-358

[10] Friedman, V. J., and Lipshitz, R. (1992), "Teaching People to Shift Cognitive Gears: Overcoming Resistance on the Road to Model II", Journal of Applied Behavioral Science, Vol. 28.1, pp. 118-136.

[11] Gregor, S., and Benbasat, I. (1999), "Explanations from Intelligent Systems: Theoretical Foundations and Implications for Practice," MIS Quarterly, Vol. 23.4, pp. 497-530.

[12] Griffith, T. L., and Northcraft, G.B. (1996), " Cognitive Elements in the Implementation of New Technology: Can Less Information Provide More Benefits?" MIS Quarterly, Vol. 20.1, pp. 99-110.

[13] Hammersley, J. S., Kadous, K., and Magro, A.M. (1997), "Cognitive and Strategic Components of the Explanation Effect", Organizational Behavior \& Human Decision Processes, May, pp. 149-158.

[14] Huber, G. P. (1983), "Cognitive Style as a Basis for MIS and DSS Design: Much Ado about Nothing", Management Science, Vol. 29.5, pp. 567-579.

[15] Ives, B., Hamilton, S., and Davis, G. B. (1980), "A Framework for Research in Computer-Based Management Information Systems," Management Science Vol. 26.9, pp. 910-934.

[16] Larkey, L. K. (1996), "Toward a Theory of Communicative Interactions in Culturally Diverse Workgroups", Academy of Management Review. Vol. 21.2, pp. 463-491.

[17] Lindsay, P.H., and Norman, D.A. (1997), Human Information Processing. 2nd Ed., New York: Academic Press.

[18] Mason, R. O., and Mitroff, I. I. (1973), "A Program for Research on Management Information Systems", Management Science, Vol. 19.1, pp. 475-487.

[19] Miller, G. A. (1956), "The Magical Number Seven, Plus or Minus Two: Some Limits on Our Capacity for Processing Information", The Psychological Review, Vol. 63.2, pp. 81-97. 
[20] Mukherjee, D., and D’Souza, D. (2003), “Think Phased Implementation for Successful Data Warehousing”, Information Systems Management, Vol. 20.2, pp. 82-90.

[21] Nevelli, K., and Mohally, D. (2004), "A Case to Examine Organisational Change", International Journal of Information Technology \& Management, Vol. 3, pp. 2-4.

[22] Newell, A. and Simon, H.A. (1972), Human Problem Solving, Englewood Cliffs, NJ: Prentice Hall.

[23] Nolan, R. L., and Wetherbe, J. C. (1980), "Toward a Comprehensive Framework of MIS Research," MIS Quarterly, Vol. 4.6, pp. 1-19.

[24] Poole, P. P (1998), "Words and deeds of organizational change," Journal of Managerial Issues, Vol. 10.1, pp. 45-59.

[25] Ramaprasad, A. (1987), "Cognitive Process as a Basis for MIS and DSS Design", Management Science, Vol. 14.2, pp. 139-148.

[26] Rao, H. R., Jacob, V., and Lin, F. (1992), "Hemispheric Specialization, Cognitive Differences, and Their Implications for the Design of Decision Support Systems", MIS Quarterly, Vol. 16.2. pp. 145-151

[27] Ratnasingam, P. (2005), "Trust In Inter-Organizational Exchanges: A Case Study in Business To Business Electronic Commerce", Decision Support Systems, Vol. 39.3, pp. 525-544.

[28] Reddy, R. (1990), "Technology and Organizations: A Technological Perspective in Technology and Organizations", P.S. Goodman, L.S. Sproull and Associates, Jossey-Bass, San Francisco, CA, pp. 232-253.

[29] Robey, D. (1983), "Cognitive Style and DSS Design: A comment on Huber's Paper", Management Science, Vol. 29.5, pp. 580-582.

[30] Robey, D., and Taggert, W. (1981), "Measuring Manager's Minds: The Assessment of Style on Human Information Processing", Academy of Management Review, Vol. 6.3, pp. 375-383.

[31] Robey, D., and Taggert, W. (1982), "Human Information Processing in Information and Decision Support Systems", MIS Quarterly, Vol. 6.2, pp. 61-73.

[32] Robey, D. (1992), "Response to Rao, et al.: More Ado about Cognitive Style and DSS Design", MIS Quarterly, Vol. 16.2, pp. 151-153

[33] Rockart, J.F., and Crescenzi, A. D. (1984), "Engaging Top Management in Information Technology," Sloan Management Review, Vol. 25.4, pp. 3-16.

[34] Schamp, E.W., Rentmeister, B., and Lo, V. (2004), "Dimensions of Proximity in Knowledge-Based Networks: The Cases of Investment Banking and Automobile Design", European Planning Studies, Vol. 12.5 , pp. 607-624

[35] Schein, E.H. (1961), Brainwashing, Cambridge, MA: Center for International Studies, MIT, 1961.

[36] Schneider, D.J. (1991), "Social Cognition," Annual Review of Psychology. Vol. 42, pp. 527-561.

[37] Shaft, T. M., and Vessey, I. (2006), "The Role of Cognitive Fit in the Relationship between Software Comprehension and Modification," MIS Quarterly, Vol. 30.1, pp. 29-55.

[38] Spence, J. W., and Tsai, R.J. (1997), "On Human Cognition and the Design of Information Systems", Information Management, Vol. 32.2, pp. 65-73.

[39] Te'eni, D. (2001), "Review: A Cognitive-Affective Model of Organizational Communication for Designing IT," MIS Quarterly, Vol. 25.2, pp. 251-312.

[40] Todd, P., and Benbasat, I. (1987), "Process Tracing Methods in Decision Support System Research: Exploring the Black Box", MIS Quarterly, Vol. 11.4, pp. 493-512.

[41] Todd, P., and Benbasat, I. (1991), "An Experimental Investigation on the Impact of Computer Based Decision Aids on Decision Making Strategies", Information Systems Research, Vol. 2.2, pp. 87-115.

[42] Vessey, I. (1991), "Cognitive Fit: A Theory-Based Analysis of the Graphs Versus Tables Literature", Decision Sciences, Vol. 22.2, pp. 219-240.

[43] Vessey, I., and Galletta, D. (1991), "Cognitive Fit: An Empirical Study of Information Acquisition", Information Systems Research, Vol. 2.1, pp. 63-84.

[44] Ward, E. A. (1998), "Managerial power bases and subordinates' manifest needs as influences on psychological climate," Journal of Business and Psychology, Vol. 12.3, pp. 361-378

[45] Zhuge, H. (2003), "Workflow - and Agent Based Cognitive Flow Management for Distributed Team Cooperation", Information \& Management, Vol. 40.5, pp. $419-429$.
Jaesung Sim is currently an assistant professor of Computer Information Systems at Mansfield University of Pennsylvania. He received his PhD in Business Computer Information Systems from University of North Texas, MS in Management Information Systems from Texas Tech University. His area of specialization include data base management Systems, data warehousing, data mining, ecommerce, cognitive process and organizational change in information systems. He has published and presented numerous papers at academic conferences.

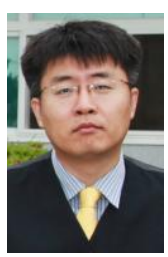

